\title{
Amla (Emblica officinalis Gaertn.) extract inhibits lipopolysaccharide-induced procoagulant and pro-inflammatory factors in cultured vascular endothelial cells
}

\author{
Theertham Pradyumna Rao ${ }^{1 *}$, Takayuki Okamoto ${ }^{2}$, Nobuyuki Akita ${ }^{2}$, Tatsuya Hayashi ${ }^{2,3}$, \\ Naomi Kato-Yasuda ${ }^{1}$ and Koji Suzuki ${ }^{2}$ \\ ${ }^{1}$ Nutrition Division, Taiyo Kagaku Company Limited, 1-3 Takaramachi, Yokkaichi, Mie 510-0844, Japan \\ ${ }^{2}$ Department of Molecular Pathobiology, Mie University Graduate School of Medicine, 2-174 Edobashi, \\ Tsu City, Mie 514-8507, Japan \\ ${ }^{3}$ Department of Biochemistry, Mie Preference College of Nursing, 1-1-1 Yumegaoka, Tsu, Mie 514-0116, Japan \\ (Submitted 19 December 2012 - Final revision received 22 April 2013 - Accepted 25 April 2013 - First published online 7 June 2013)
}

\section{Abstract}

Amla (Emblica officinalis Gaertn.) has been used for many centuries in traditional Indian Ayurvedic formulations for the prevention and treatment of many inflammatory diseases. The present study evaluated the anti-inflammatory and anticoagulant properties of amla fruit extract. The amla fruit extract potentially and significantly reduced lipopolysaccharide (LPS)-induced tissue factor expression and von Willebrand factor release in human umbilical vein endothelial cells (HUVEC) in vitro at clinically relevant concentrations (1-100 $\mu \mathrm{g} / \mathrm{ml})$. In a leucocyte adhesion model of inflammation, it also significantly decreased LPS-induced adhesion of human monocytic cells (THP-1) to the HUVEC, as well as reduced the expression of endothelial-leucocyte adhesion molecule-1 (E-selectin) in the target cells. In addition, the in vivo anti-inflammatory effects were evaluated in a LPS-induced endotoxaemia rat model. Oral administration of the amla fruit extract ( $50 \mathrm{mg} / \mathrm{kg}$ body weight) significantly decreased the concentrations of pro-inflammatory cytokines, TNF- $\alpha$ and IL- 6 in serum. These results suggest that amla fruit extract may be an effective anticoagulant and anti-inflammatory agent.

\section{Key words: Amla: Adhesion: Blood coagulation: Endothelial cells: Inflammation}

Emblica officinalis Gaertn. (also called Phyllanthus emblica), commonly known as amla, is colloquially referred to as Indian Gooseberry in the West and as a rasayana in the Indian traditional Ayurvedic medicine literature. In particular, the pulp of the fruit has been used in various Ayurvedic formulations for the treatment and prevention of various maladies for centuries ${ }^{(1-3)}$. Various animal and clinical studies have provided a scientific basis for the rejuvenating and curative properties of amla ${ }^{(4-6)}$. In the present study, we evaluated the potential use of amla fruit extract for the treatment or prevention of CVD by measuring the pro-inflammatory markers in human endothelial cells (EC) during inflammation and in endotoxaemia rats.

EC are important modulators of vascular inflammation and thrombosis $^{(7,8)}$. Aberrant EC function has been linked to hypertension, arterial or venous thrombosis, and atherosclerosis $^{(9,10)}$. Tissue factor (TF) expressed on the surface of EC, macrophages and monocytes activates the coagulation system via the extrinsic clotting pathway ${ }^{(11,12)}$. The von Willebrand factor (vWF), which binds to the coagulation factor VIII, is important for thrombus stabilisation ${ }^{(13)}$. The vWF is synthesised and released from the Weibel-Palade bodies of $\mathrm{EC}^{(14)}$. Thrombin, histamine, lipopolysaccharide (LPS) and other mediators, which induce the expression of $\mathrm{TF}$ and release of the vWF from EC, are important for modulating coagulation and platelet function ${ }^{(14)}$.

Activated EC express pro-inflammatory cytokines, chemokines and adhesion molecules required for the recruitment of leucocytes into the damaged endothelium. The migration of leucocytes to the site of inflammation is regulated by the expression of cell adhesion molecules such as intercellular adhesion molecule-1, vascular cell adhesion molecule- 1 and E-selectin $^{(15)}$. The cell adhesion molecules of EC are induced by inflammatory mediators, such as TNF- $\alpha$, IL-1 $\beta$ and LPS $^{(16)}$. The increased expression of cell adhesion molecules on EC alters the adhesive property of the vascular

Abbreviations: EC, endothelial cell; GAPDH, glyceraldehyde-3-phosphate dehydrogenase; HUVEC, human umbilical vein endothelial cells; LPS, lipopolysaccharide; TF, tissue factor; vWF, von Willebrand factor.

*Corresponding author: T. P. Rao, email tprao@taiyokagaku.co.jp 
endothelium and may lead to an indiscriminate infiltration of leucocytes and endothelial inflammation ${ }^{(17)}$. Therefore, anticoagulant and anti-inflammatory drugs are often employed in patients with cardiovascular and inflammatory diseases. Previous studies have suggested amla fruit extract to have cytoprotective, antioxidant and anti-inflammatory activities ${ }^{(4-6)}$. However, the anticoagulant and anti-inflammatory effects of amla fruit extract on endothelial function are poorly understood.

In the present study, we evaluated the effects of amla fruit extract on LPS-induced TF expression, vWF release and E-selectin expression in human umbilical EC (HUVEC). In addition, a LPS-induced endotoxaemia rat model was used to evaluate the anti-inflammatory effects of amla fruit extract in vivo.

\section{Materials and methods}

\section{Cell culture}

Primary HUVEC and the respective culture media were purchased from Sanko Junyaku. The HUVEC were cultured in collagen-coated $100 \mathrm{~mm}$ tissue-culture dishes (Becton Dickinson) in an atmosphere containing a mixture of $95 \%$ air and $5 \% \mathrm{CO}_{2}$. Human monocytic cell line THP-1 cells were cultured on Roswell Park Memorial Institute-1640 medium (Invitrogen) supplemented with 10\% fetal bovine serum.

\section{Preparation of amla fruit extract}

The test material was a commercial amla fruit extract (SunAmla, Taiyo Kagaku Company, Limited). The extract was prepared by processing the fruit pulp to obtain clarified juice through a patented enzymatic process. The clarified juice was spraydried and used as an amla fruit extract. The extract was composed of carbohydrates $(81.3 \%)$, fibres $(5 \cdot 2 \%)$, minerals $(2 \cdot 9 \%)$, proteins $(2.5 \%)$, fats $(0 \cdot 1 \%)$ and moisture $(8.0 \%)$. Among these components, vitamin C (3.0\%) and polyphenols (30.0\%) were identified as the functional components. The product was completely soluble in water.

\section{Measurement of tissue factor activity}

TF activity was measured as a factor of $\mathrm{X}$ activation by factor VIIa and TF complex in HUVEC after stimulation with TNF- $\alpha^{(18)}$. Briefly, the HUVEC (twenty-four-well plate, $1.0 \times 10^{5}$ cells/well) were cultured until $90 \%$ confluence was reached and incubated overnight in a serum-free medium. The cells were stimulated with $1 \mu \mathrm{g} / \mathrm{ml}$ of stimulant LPS (Sigma) in the presence of $0,3,10,30$ and $100 \mu \mathrm{g} / \mathrm{ml}$ of the amla fruit extract for $4 \mathrm{~h}$. The cells were washed twice with HEPES-buffered saline (20 mm-HEPES and $150 \mathrm{~mm}-\mathrm{NaCl}, \mathrm{pH}$ 7.5) containing $5 \mathrm{mmol} / \mathrm{l} \mathrm{CaCl}_{2}$ and then incubated with

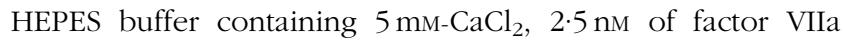
and $500 \mathrm{~nm}$ of factor $\mathrm{X}$ for $1 \mathrm{~h}$ at $37^{\circ} \mathrm{C}$. The generation of factor X was measured using $200 \mu \mathrm{M}$ of a synthetic substrate (Boc-Ile-Glu-Gly-Arg-MCA, code 3094 V; Peptide Institute) after incubation for $3 \mathrm{~min}$ at room temperature. Fluorescence intensity was determined by measuring the excitation wavelength at $394 \mathrm{~nm}$ and the fluorescence wavelength at $444 \mathrm{~nm}$ in a fluorescence microplate reader (Molecular Devices).

\section{Measurement of the von Willebrand factor antigen}

After the stimulation of the HUVEC with LPS at various concentrations $(0,3,10,30$ and $100 \mu \mathrm{g} / \mathrm{ml})$ of the amla fruit extract, the concentration of the VWF antigen in the supernatant was determined with ELISA. The ELISA method involved coating of plates (MaxiSorpTM, Nunc A/S) with polyclonal rabbit anti-human vWF (Dako) as a capture antibody. In brief, $100 \mu \mathrm{l}$ of the supernatant from HUVEC treated with LPS were collected and placed into preblocked microtitre wells. After incubation for $2 \mathrm{~h}$, the wells were washed three times with TBS containing 0.05\% Tween-20 and TBS, respectively, and then incubated with horseradish peroxidase-conjugated anti-vWF antibodies (Dako) (1:500 in TBS) for $2 \mathrm{~h}$. The wells were again washed three times with TBS containing 0.05\% Tween-20 and TBS, respectively, and then the substrate (o-phenylenediamine, Sigma) was added. After 10-15 min of substrate conversion, the reactions were stopped with $50 \mu \mathrm{l}$ of $1 \mathrm{M}-\mathrm{H}_{2} \mathrm{SO}_{4}$, and the plates were read at $490 \mathrm{~nm}$.

\section{Cell adhesion assay}

The HUVEC were grown until confluence was reached on a collagen-coated ninety-six-well plate and incubated in a serum-free medium overnight. These HUVEC were stimulated with $1 \mu \mathrm{g} / \mathrm{ml}$ of stimulant LPS for $2 \mathrm{~h}$ along with different concentrations $(0,1$, $3,10,30$ and $100 \mu \mathrm{g} / \mathrm{ml}$ ) of the amla fruit extract. The THP- 1 cells were labelled with $1 \mu \mathrm{g} / \mathrm{ml}$ of Calcein-AM (Dojindo Laboratories) for $30 \mathrm{~min}$ and rinsed three times with adequate amounts of PBS to remove background fluorescence. The HUVEC were washed with PBS and then mixed with $100 \mu$ l of a THP- 1 cell suspension $\left(1 \times 10^{5}\right.$ cells $\left./ \mathrm{ml}\right)$. After incubation for $4 \mathrm{~h}$, the supernatant was washed with PBS to remove the detached cells. The adherent cells were measured through fluorescence intensity at $485 \mathrm{~nm}$ and emission wavelength at $538 \mathrm{~nm}$ using a fluorescence microplate reader.

\section{Analysis of mRNA expression}

The mRNA expression was analysed using RT-PCR. Total RNA of the HUVEC was prepared using the TRIzol reagent (Life Technologies) after stimulation of the cells with LPS at different concentrations $(0,3,10,30$ and $100 \mu \mathrm{g} / \mathrm{ml})$ of the amla fruit extract. Complementary DNA was prepared using the SuperScript first-strand synthesis system for RT-PCR following the manufacturer's instructions (Life Technologies). For quantitative PCR, amplifications of the E-selectin gene were performed on the ABI PRISM 7300 Real-Time PCR system using Platinum SYBR Green qPCR SuperMix (Life Technologies). The forward and reverse primers for E-selectin and glyceraldehyde-3-phosphate dehydrogenase (GAPDH) were 5'-CAT TGT GGC CAA GGA GAT CTG-3' and 5'-CTT CGG AGT TTG GGT TTG CTT- $3^{\prime}$ and $5^{\prime}$-ATC ATC CCT GCC TCT ACT GG-3' and 5'-GTC AGG TCC ACC ACT GAC AC-3', respectively. The forward and reverse primers for E-selectin 
were $5^{\prime}$-AAA ACT TCC ATG AGG CCA AA- $3^{\prime}$ and $5^{\prime}$-GCA TTC CTC TCT TCC AGA GC- $3^{\prime}$, respectively. The forward and reverse primers for GAPDH were $5^{\prime}$-ATC ATC CCT GCC TCT ACT GG-3' and $5^{\prime}$-GTC AGG TCC ACC ACT GAC AC-3', respectively. The GAPDH gene was used as the internal control.

\section{Analysis of cytokine concentrations in endotoxaemia rat serum}

The 'Guidelines for Animal Experimentation' approved by the Mie University, Japan, was followed during the experiments. Endotoxaemia was induced in the rats by intraperitoneal injection of LPS as described previously ${ }^{(19)}$. In brief, healthy male Wistar rats ( 8 weeks old, $n$ 40) were grouped into an amla group ( $n$ 20) and a control group ( $n$ 20). The rats in the amla group were orally injected with the amla fruit extract $(50 \mathrm{mg} / \mathrm{kg}$ body weight). At $5 \mathrm{~min}$ after injection, the rats in both the groups were intraperitoneally injected with LPS at a dose of $2 \mathrm{mg} / \mathrm{kg}$ body weight. After the injection of LPS, the rats $(n 5)$ in each group were killed at $0,4,8$ and $24 \mathrm{~h}$ time intervals and serum samples were collected. The serum samples were then stored at $-80^{\circ} \mathrm{C}$ until used. The concentrations of the inflammatory mediators IL- 6 or TNF- $\alpha$ in rat serum were measured using commercial ELISA kits (BD Biosciences)

\section{Statistical analysis}

In vitro experimental data were collected from two or three independent experiments, where each experiment comprised three or five replications of each treatment. The means and standard deviations for replicate experiments were determined and compared using Dunnett's or unpaired $t$ tests. $P<0.05$ was considered statistically significant. In the case of the in vivo experiments, data were collected from five individual samples and expressed as means and standard deviations. The data were compared using the unpaired $t$ test, and $P<0 \cdot 05$ was considered statistically significant.

\section{Results}

\section{Effects on lipopolysaccharide-induced blood coagulation activity}

In vitro LPS-induced TF expression and $\mathrm{VWF}$ release in the HUVEC at various concentrations of the amla fruit extract are shown in Fig. 1(a). LPS-induced TF expression in the HUVEC was significantly $(P<0.05)$ decreased in a dosedependent manner at concentrations greater than $10 \mu \mathrm{g} / \mathrm{ml}$ of the amla fruit extract. Moreover, LPS-induced vWF release in the HUVEC was also significantly inhibited $(P<0.05)$ at a concentration of $100 \mu \mathrm{g} / \mathrm{ml}$ of the amla fruit extract (Fig. 1(b)). These data indicate that amla fruit extract may decrease LPS-induced TF expression and $\mathrm{VWF}$ release in HUVEC.
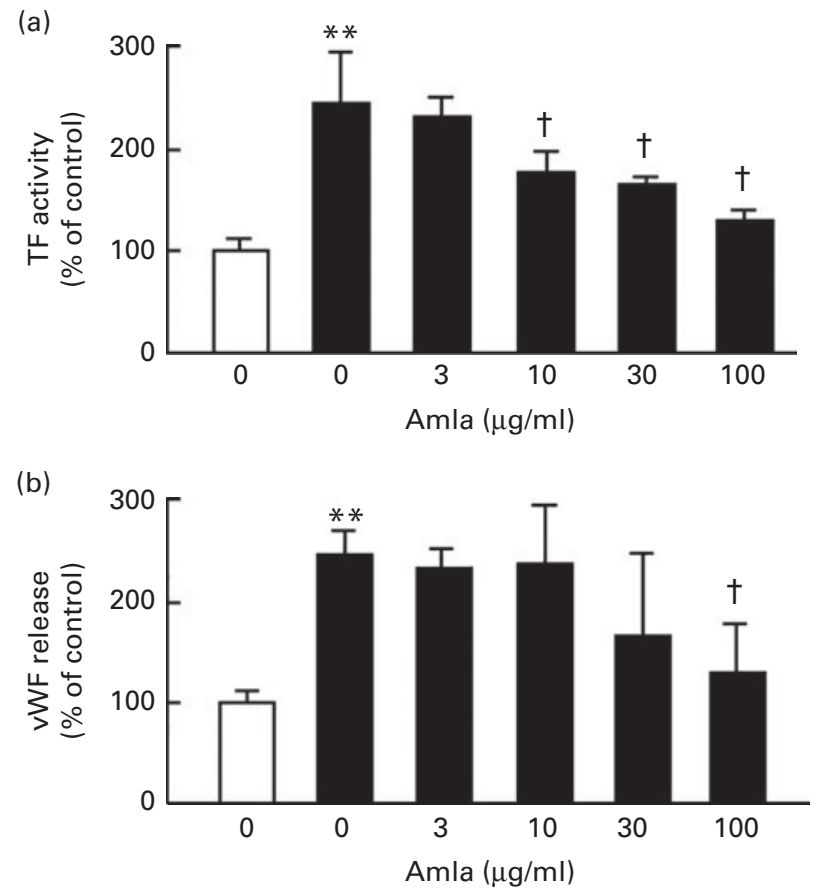

Fig. 1. Effects of amla fruit extract on lipopolysaccharide (LPS)-induced coagulant activity in human umbilical vein endothelial cells (HUVEC). (a) Tissue factor (TF) activity of HUVEC stimulated with $1 \mu \mathrm{g} / \mathrm{ml}$ LPS ( $\square$ ) or PBS $(\square)$ in the presence of $0-100 \mu \mathrm{g} / \mathrm{ml}$ of amla fruit extract was determined. (b) von Willebrand factor (VWF) release from HUVEC into the supernatant was determined by ELISA. Values are means of three independent experiments, with standard deviations represented by vertical bars. ${ }^{* *}$ Mean value was significantly different from that of the PBS control $(P<0.01$; Dunnett's test). † Mean value was significantly different from that of the LPS-stimulated HUVEC without amla fruit extract $(P<0.05$; Dunnett's test).

Effects on lipopolysaccharide-induced adhesion of THP-1 cells to human umbilical vein endothelial cells

Using a fluorescent labelling technique, the effect of amla fruit extract on the adhesion of monocytes to EC was measured. The HUVEC were pre-incubated with LPS in the presence of the amla fruit extract. The number of THP-1 cells adhered to the HUVEC was significantly decreased $(P<0.05)$ with increased concentrations of the amla fruit extract (Fig. 2). The results show that amla fruit extract may decrease the adhesion of THP-1 cells to LPS-activated HUVEC.

\section{Effects on lipopolysaccharide-induced expression of E-selectin MRNA in human umbilical vein endothelial cells}

LPS-induced E-selectin mRNA expression in the HUVEC was evaluated through RT-PCR analysis. As shown in Fig. 3, the amla fruit extract at dosages of 30 and $100 \mu \mathrm{g} / \mathrm{ml}$ significantly decreased $(P<0.05)$ LPS-induced E-selectin mRNA expression in HUVEC when compared with E-selectin mRNA expression in LPS-treated HUVEC without the amla fruit extract. These results suggest that amla fruit extract suppresses the adhesion of THP-1 cells to HUVEC by reducing E-selectin expression in HUVEC. 


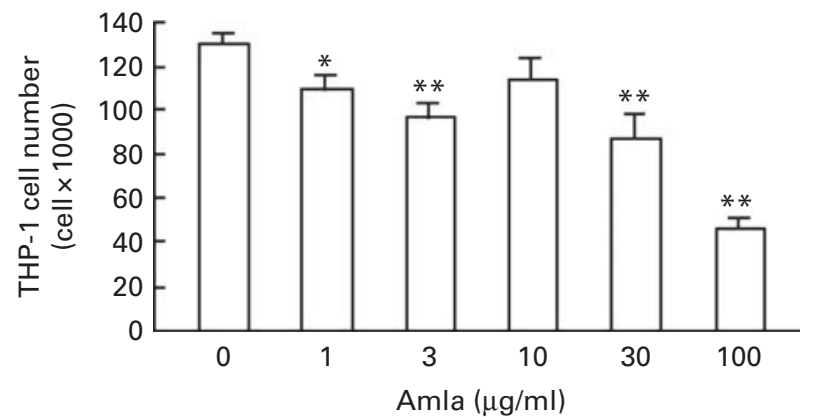

Fig. 2. Effects of amla fruit extract on the adhesion of THP-1 cells to human umbilical vein endothelial cells (HUVEC). HUVEC were stimulated with lipopolysaccharide in the presence of $0-100 \mu \mathrm{g} / \mathrm{ml}$ of amla fruit extract. The number of THP-1 cells adhered to the HUVEC was determined. Values are means of three independent experiments, with standard deviations represented by vertical bars. Mean values were significantly different compared with those of the group stimulated in the absence of amla fruit extract: ${ }^{*} P<0.05 ;{ }^{*} P<0.01$ (Dunnett's test).

\section{Effects on lipopolysaccharide-induced cytokine expression in vivo}

Endotoxaemia was induced by injecting LPS $(2 \mathrm{mg} / \mathrm{kg})$ intraperitoneally. In this in vivo model, the effect of oral administration of amla fruit extract $(50 \mathrm{mg} / \mathrm{kg}$ body weight) on systemic inflammation was evaluated by measuring the concentrations of TNF- $\alpha$ and IL- 6 in the serum samples. The concentrations of TNF- $\alpha$ and IL- 6 in serum were significantly decreased $(P<0.05)$ after oral administration of the amla fruit extract by $4-8 \mathrm{~h}$ after induction of inflammation with LPS (Fig. 4). These results suggest that the anti-inflammatory activity of amla fruit extract is due to the suppression of the expression of pro-inflammatory cytokines.

\section{Discussion}

Ayurveda, the Indian traditional medicine, which has been in practice for centuries, may provide potential therapeutics for a variety of maladies ${ }^{(1-3)}$. As most of the Ayurvedic formulations contain amla preparations, identifying the mechanism of action is clearly important. The amla fruit contains high levels of vitamin $\mathrm{C}$, tannins, polyphenols (gallic acid and ellagic acid), minerals, fibres, proteins and amino acids such as glutamic acid, proline, aspartic acid, alanine, cystine and lysine ${ }^{(20,21)}$. Recently, several hydrolysable tannins, flavonoids and alkaloids have been identified in amla ${ }^{(22-24)}$. Although vitamin C, gallic acid and ellagic acid present in amla are known to be potent antioxidants, the function of other components is unknown. In the present study, we used a water-soluble amla fruit extract, which was prepared through a patented enzymatic process to retain all its active components such as vitamin C (3\%) and polyphenols (30\%). The effect of amla fruit extract on LPS-induced procoagulant and proinflammatory responses was examined in vitro and in vivo.

The EC lining is an important physical and functional barrier to invading pathogens circulating in the blood stream ${ }^{(25)}$. This lining has a remarkable role in homeostasis, including vasoregulation and selective vascular permeability, and provides an anticoagulant surface ${ }^{(26)}$. During chronic infections,

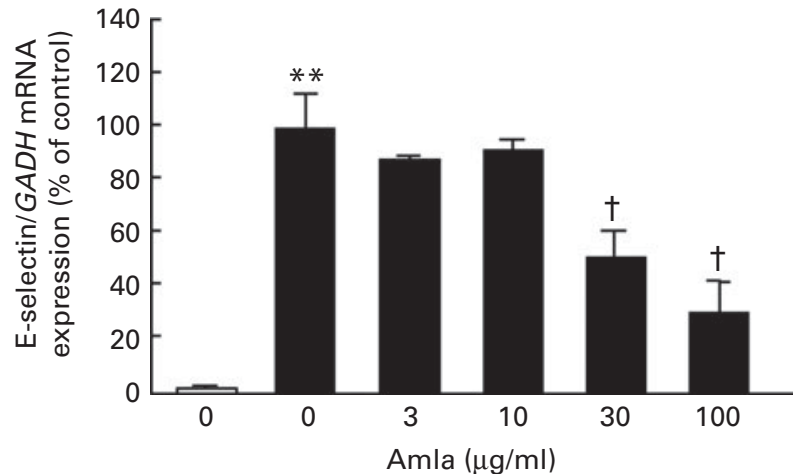

Fig. 3. Effects of amla fruit extract on lipopolysaccharide (LPS)-induced E-selectin expression in human umbilical vein endothelial cells (HUVEC). E-selectin mRNA expression of HUVEC stimulated with $1 \mu \mathrm{g} / \mathrm{ml}$ LPS ( $)$ or PBS $(\square)$ in the presence of $0-100 \mu \mathrm{g} / \mathrm{ml}$ of amla fruit extract was examined. Values are means of two independent experiments, with standard deviations represented by vertical bars. ${ }^{* *}$ Mean value was significantly different from that of the PBS control $(P<0.01$; Dunnett's test). † Mean value was significantly different from that of the LPS-stimulated HUVEC without amla fruit extract ( $P<0.05$; Dunnett's test). GAPDH, glyceraldehyde-3-phosphate dehydrogenase.

the endothelium may be discomposed and its normal physiological functions may be disturbed, contributing to vascular dysfunction $^{(26)}$.

LPS, the major surface component of Gram-negative bacteria, is a potent initiator of inflammatory responses and serves as a surrogate for a bacterial infection ${ }^{(27)}$. LPS triggers the procoagulant and pro-inflammatory responses of EC and causes systemic inflammatory responses such as sepsis ${ }^{(28-31)}$. LPS induces TF

(a)

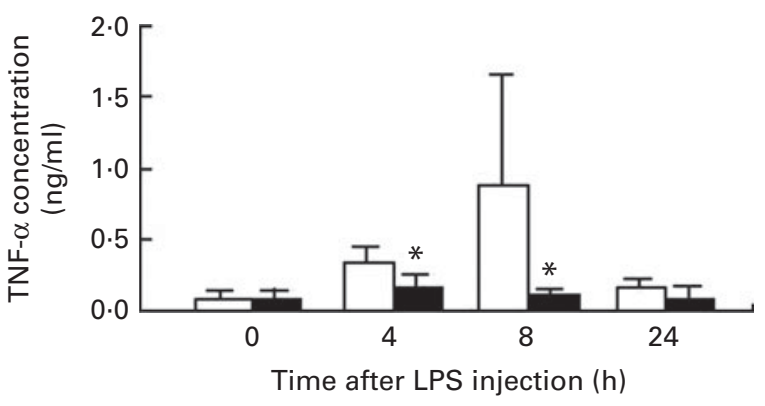

(b)

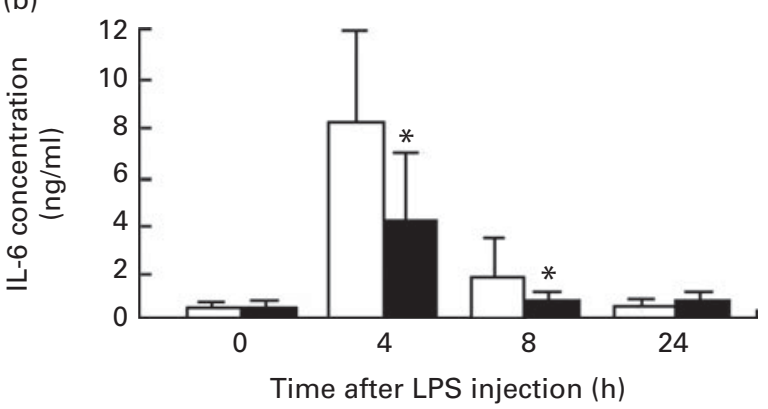

Fig. 4. Effects of amla fruit extract on lipopolysaccharide (LPS)-induced cytokine expression in vivo. Serum concentrations of (a) TNF- $\alpha$ and (b) IL-6 of endotoxaemia model rats $(n 5)$ given $50 \mathrm{mg} / \mathrm{kg}$ body weight of amla fruit extract $(\square)$ or PBS $(\square)$ by oral administration were measured. Values are means of five individual samples, with standard deviations represented by vertical bars. ${ }^{*}$ Mean values were significantly different from those of timematched PBS-injected rats $(P<0.05$; unpaired $t$ test). 
expression and $\mathrm{vWF}$ release in EC to initiate the blood coagulation cascade. On the other hand, LPS induces the expression of inflammatory mediators, such as TNF- $\alpha$, IL- $1 \beta$, interferons and other mediators ${ }^{(11-13)}$. In addition to EC, macrophages, neutrophils and immune cells also express inflammatory mediators. These mediators can increase TF expression and vWF release and then enhance inflammatory responses involving the expression of cytokines and chemokines and leucocyte adhesion $^{(8-10)}$. High levels of plasma TF antigen were detected in patients with disseminated intravascular coagulation, suggesting that the enhancement of TF production by EC may be important for the progression of disseminated intravascular coagulation $^{(12)}$. As such, therapeutics that can target the reduction of TF production may be important anti-inflammatory and anticoagulant agents.

The amla fruit extract significantly inhibited LPS-induced TF expression in the HUVEC (Fig. 1(a)) in vitro. Oral administration of amla fruit extract in rats with LPS-induced endotoxaemia suppressed IL-6 and TNF- $\alpha$ production in serum (Fig. 4). Moreover, the amla fruit extract suppressed the adhesion of THP-1 cells to EC by reducing E-selectin expression in the HUVEC (Fig. 3). Asmawi et al. ${ }^{(32)}$ reported the anti-inflammatory and anti-migration activities of $E$. officinalis in human polymorphonuclear leucocytes. Collectively, these data suggest that amla fruit extract or individual components of amla may be used as anticoagulant and anti-inflammatory agents to modulate EC function.

The initiation and progression of thrombus formation are mediated through the adhesive protein vWF, which in turn plays a critical role in the tethering and adhesion of platelets to subendothelial surfaces and platelet aggregation ${ }^{(13)}$. As the amla fruit extract inhibited LPS-induced vWF release from the HUVEC (Fig. 1(b)), it may be used to decrease the release of $\mathrm{VWF}$ and to suppress the progression of platelets.

Amla is a potent rasayana in Ayurveda for treatment and prevention intervention against inflammatory diseases. Previously, the anti-inflammatory activity of amla leaf extract ${ }^{(32,33)}$ and fruit extract ${ }^{(34)}$ had been observed in experimental rat models. Amla has several potent antioxidants such as vitamin $\mathrm{C}$, gallic acid, ellagic acid and complex structured tannins, which have been recognised for their antioxidant ${ }^{(35)}$, dyslipidaemic $^{(36)}$, anti-carcinogenic ${ }^{(37)}$, cytoprotective ${ }^{(38)}$, anti-diabetic $^{(39)}$ and antimicrobial properties ${ }^{(40)}$. Although previous studies have indicated the anti-inflammatory activity of amla ${ }^{(32-34)}$, the relationship of such an activity with its components is not fully characterised. Although the present study elucidated the anticoagulant, anti-inflammatory and anti-platelet aggregation activities of amla fruit extract, further studies are warranted to investigate the relative contribution of the individual components. In conclusion, the present in vitro and in vivo studies provide a scientific mechanistic basis for the historical use of amla. The combined anti-inflammatory, anticoagulant and anti-platelet activities of amla are attractive for its use in the prevention and treatment of a variety of vascular disorders.

\section{Acknowledgements}

We sincerely acknowledge Dr D. C. Chu, Retired General Manager of Taiyo Kagaku, for coordinating with Mie University to conduct this joint research and to avail its facilities and assistance in this project. We also thank the Government of Japan for providing a grant (no. 00432-017) through Tokai Plaza for conducting the research and development of food materials for the prevention of angiopathic lifestyle-related disease. T. P. R. initiated and executed the project and wrote the manuscript. T. O., N. A., T. H. and N. K.-Y. conducted the experimental work. K. S. was the collaborator and advisor of the research work. The authors state that there is no conflict of interest.

\section{References}

1. Krishnaveni M \& Mirunalini S (2010) Therapeutic potential of Phyllanthus emblica (amla): the ayurvedic wonder. J Basic Clin Physiol Pharmacol 21, 93-105.

2. Chen TS, Liou SY \& Chang YL (2009) Supplementation of Emblica officinalis (Amla) extract reduces oxidative stress in uremic patients. Am J Chin Med 37, 19-25.

3. Rege NN, Thatte UM \& Dahanukar SA (1999) Adaptogenic properties of six rasayana herbs used in Ayurvedic medicine. Phytother Res 13, 275-291.

4. Kumar NP, Annamalai AR \& Thakur RS (2009) Antinociceptive property of Emblica officinalis Gaertn (Amla) in high fat diet-fed/low dose streptozotocin induced diabetic neuropathy in rats. Indian J Exp Biol 47, 737-742.

5. Nicolis E, Lampronti I, Dechecchi MC, et al. (2008) Pyrogallol, an active compound from the medicinal plant Emblica officinalis, regulates expression of pro-inflammatory genes in bronchial epithelial cells. Int Immunopharmacol $\mathbf{8}$, $1672-1680$.

6. Sai Ram M, Neetu D, Deepti P, et al. (2003) Cytoprotective activity of amla (Emblica officinalis) against chromium (VI) induced oxidative injury in murine macrophages. Phytother Res 17, 430-433.

7. Steffens S \& Mach F (2004) Inflammation and atherosclerosis. Herz 29, 741-748.

8. Levi M \& van der Poll T (2010) Inflammation and coagulation. Crit Care Med 38, S26-S34.

9. Sprague AH \& Khalil RA (2009) Inflammatory cytokines in vascular dysfunction and vascular disease. Biochem Pharmacol 78, 539-552.

10. Vanhoutte PM, Shimokawa H, Tang EH, et al. (2009) Endothelial dysfunction and vascular disease. Acta Physiol (Oxf) 196, 193-222.

11. Nemerson Y (1988) Tissue factor and hemostasis. Blood $\mathbf{7 1}$, $1-8$.

12. Wada H, Wakita Y \& Shiku H (1995) Tissue factor expression in endothelial cells in health and disease. Blood Coagul Fibrinolysis 6, S26-S31.

13. Ruggeri ZM (2001) Structure of von Willebrand factor and its function in platelet adhesion and thrombus formation. Best Pract Res Clin Haematol 14, 257-279.

14. Palmer DS, Aye MT, Ganz PR, et al. (1994) Adenosine nucleotides and serotonin stimulate von Willebrand factor release from cultured human endothelial cells. Thromb Haemost 72, 132-139.

15. Bochner BS, Luscinskas FW, Gimbrone MA, et al. (1991) Adhesion of human basophils, eosinophils, and neutrophils to interleukin 1-activated human vascular endothelial cells: 
contributions of endothelial cell adhesion molecules. $J$ Exp Med 173, 1553-1557.

16. Springer TA (1994) Traffic signals for lymphocyte recirculation and leukocyte emigration: the multistep paradigm. Cell 76, 301-314.

17. Mantovani A, Bussolino F \& Introna M (1997) Cytokine regulation of endothelial cell function: from molecular level to the bedside. Immunol Today 18, 231-240.

18. Deguchi H, Takeya H, Wada H, et al. (1997) Dilazep, an antiplatelet agent, inhibits tissue factor expression in endothelial cells and monocytes. Blood 90, 2345-2356.

19. Kishiwada M, Hayashi T, Yuasa H, et al. (2008) Regulatory mechanisms of C4b-binding protein (C4BP) alpha and beta expression in rat hepatocytes by lipopolysaccharide and interleukin-6. J Thromb Haemost 11, 1858-1867.

20. Patel SS \& Goyal RK (2012) Emblica officinalis Geart: a comprehensive review on phytochemistry, pharmacology and ethnomedicinal uses. Res J Med Plant 6, 6-16.

21. Barthakur NN \& Arnold NP (1991) Chemical analysis of the emblic (Phyllanthus emblica L.) and its potential as a food source. Sci Hortic 47, 99-105.

22. Ghosal S, Tripati VK \& Chauhan S (1996) Active constituents of Emblica officinalis: part 1 - the chemistry and antioxidant effects of two new hydrolysable tannins, emblicanin A and B. Indian J Chem 3, 941-948.

23. Zhang YJ, Tanaka T, Yang CR, et al. (2001) New phenolic constituents from the fruit juice of Phyllanthas emblica. Chem Pharm Bull (Tokyo) 49, 537-540.

24. Zhang YJ, Abe T, Tanaka T, et al. (2001) Phyllanemblinins A-F, new ellagitannins from Phyllanthus emblica. I Nat Prod 64, 1527-1532.

25. Jaffe EA (1987) Cell biology of endothelial cells. Hum Pathol 18, 234-239.

26. Grandel U \& Grimminger F (2003) Endothelial responses to bacterial toxins in sepsis. Crit Rev Immunol 23, 267-299.

27. Volk T \& Kox WJ (2000) Endothelium function in sepsis. Inflamm Res 49, 185-198.

28. Calandra T (2001) Pathogenesis of septic shock: implications for prevention and treatment. J Chemother 1, 173-180.
29. Dauphinee SM \& Karsan A (2006) Lipopolysaccharide signaling in endothelial cells. Lab Invest 86, 9-22.

30. Erlich J, Fearns C, Mathison J, et al. (1999) Lipopolysaccharide induction of tissue factor expression in rabbits. Infect Immun 67, 2540-2546.

31. Levi M (2010) The coagulant response in sepsis and inflammation. Hamostaseologie 30, 10-12.

32. Asmawi MZ, Kankaanranta H, Moilanen E, et al. (1993) Anti-inflammatory activities of Emblica officinalis Gaertn leaf extracts. J Pharm Pharmacother 45, 581-584.

33. Ihantola-Vormisto A, Summanen J, Kankaanranta H, et al. (1997) Anti-inflammatory activity of extracts from leaves of Phyllanthus emblica. Planta Med 63, 518-524.

34. Jaijoy K, Soonthornchareonnon N, Panthong A, et al. (2010) Anti-inflammatory and analgesic activities of the water extract from the fruit of Phyllanthus emblica Linn. Int J App Res Nat Prod 3, 28-35.

35. Rao TP, Sakaguchi N, Juneja LR, et al. (2005) Amla (Embica officianalis Gaertn.) extracts reduce oxidative stress in streptozotocin-induced diabetic rats. J Med Food $\mathbf{8}$, 362-368.

36. Yokozawa T, Kim HY, Kim HJ, et al. (2007) Amla (Emblica officinalis Gaertn.) prevents dyslipidaemia and oxidative stress in the ageing process. Br J Nutr 97, 1187-1195.

37. Baliga MS \& Dsouza JJ (2011) Amla (Emblica officinalis Gaertn), a wonder berry in the treatment and prevention of cancer. Eur J Cancer Prev 20, 225-239.

38. Reddy VD, Padmavathi P, Gopi S, et al. (2010) Protective effect of Emblica officinalis against alcohol-induced hepatic injury by ameliorating oxidative stress in rats. Indian J Clin Biochem 25, 419-424.

39. Akhtar MS, Ramzan A, Ali A, et al. (2011) Effect of Amla fruit (Emblica officinalis Gaertn.) on blood glucose and lipid profile of normal subjects and type 2 diabetic patients. Int J Food Sci Nutr 62, 609-616.

40. Saeed S \& Tariq P (2007) Antibacterial activities of Emblica officinalis and Corandrum stivum against gram negative urinary pathogens. Pak J Pharm Sci 20, 32-35. 